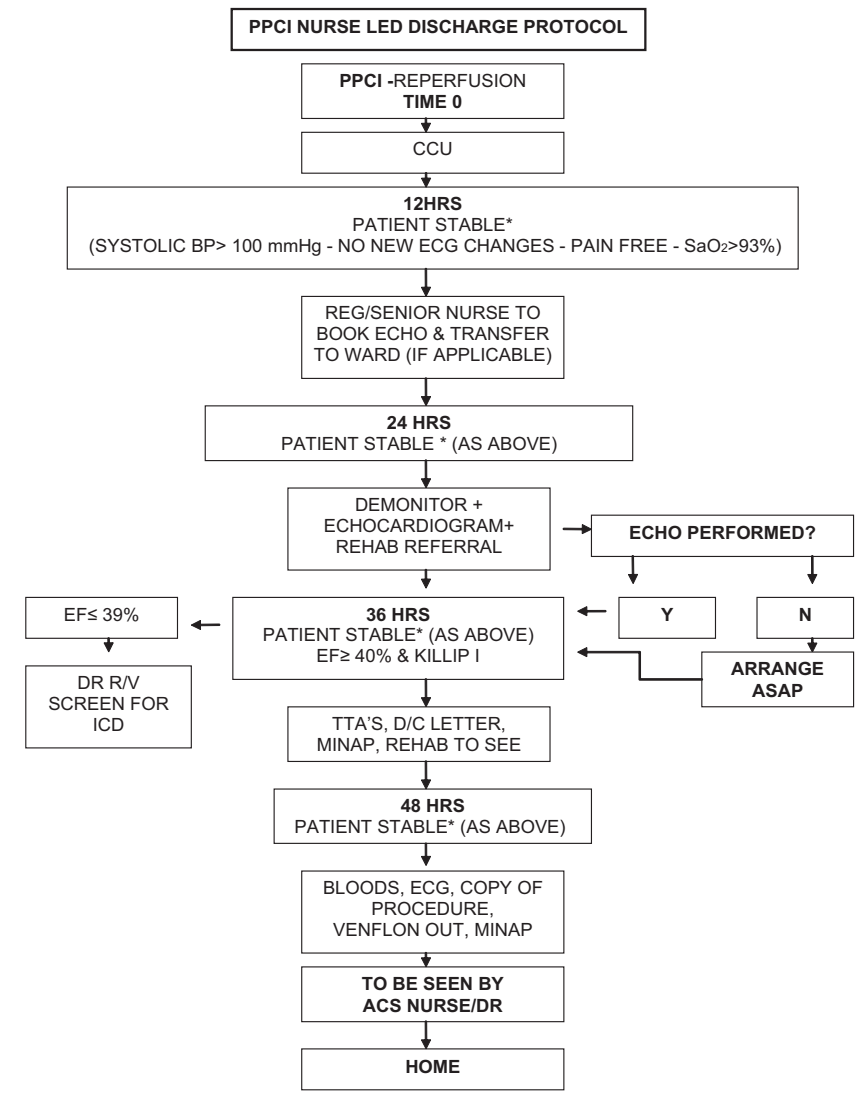

* IF PATIENT UNSTABLE AT ANY STAGE PLEASE D/W DR/ACS NURSE

Abstract 80 Figure $1 \mathrm{PPCl}$ nurse LED discharge protocol.

\section{DYSSYNCHRONOUS THREE PLANE MOTION AND IMPAIRED LEFT VENTRICULAR TWIST IN PATIENTS WITH HEART FAILURE AND NORMAL EJECTION FRACTION}

doi:10.1136/heartjnl-2011-300198.81

${ }^{1} Y$ T Tan, ${ }^{2} \mathrm{~F}$ W G Wenzelburger, ${ }^{3} \mathrm{~F}$ Leyva, ${ }^{3} \mathrm{~J}$ E Sanderson. ${ }^{1}$ Department of Cardiovascular Medicine, Birmingham, UK; ${ }^{2}$ Institute for Science and Technology in Medicine, Keele University, Stoke on Trent, Keele, UK; ${ }^{3}$ Department of Cardiovascular Medicine, University of Birmingham, Birmingham, UK

Background The pathophysiology of heart failure with normal ejection fraction (HFNEF) is complex and not fully understood. Recent publications showed a loss of apical rotation and longitudinal function particularly on exercise in these patients. Whether a deterioration of basal rotation and a dyssynchrony of different three plane motions on exercise might contribute to symptoms in these patients is not known.

Method 72 Patients (age 73 \pm 7 years, 48 female) with breathlessness on exertion and normal EF ( $60 \pm 7 \%)$ underwent cardiopulmonary exercise test to rule out alternative clinical reasons $\left(\mathrm{VO}_{2} \mathrm{max}\right.$ $18.4 \pm 4.9 \mathrm{ml} / \mathrm{min} / \mathrm{kg})$. Data were compared to 38 age-matched control subjects (age $71 \pm 7$ years, 29 female, EF $63 \pm 7 \%$ ) with a normal exercise tolerance $\left(\mathrm{VO}_{2} \max 28.6 \pm 5.1 \mathrm{ml} / \mathrm{min} / \mathrm{kg}\right)$. All underwent full Doppler 2D-echocardiography at rest and on supine exercise. Echo images were analysed off-line. Apical and basal rotation, longitudinal and radial displacement were measured by speckle tracking. Speckle tracking pictures and colour TDI curves were loaded into custom made software. The software interpolated all curves and calculated twist as the difference of rotation at apex and at base. The software offered timing information to calculate SD and time delays for different motions.
Results As previously described apical rotation was reduced at rest and on exercise Basal rotation was comparable at rest but significantly reduced on exercise in patients. The SD for four different systolic peak motions (basal and apical rotation, longitudinal and radial displacement) was comparable at rest but on exercise controls showed a significantly reduced SD compared to patients showing a greater ability to synchronise motions. Furthermore a ratio of untwist during IVRT and longitudinal extension (Ratio Untwist /Extension in IVRT) showed a significant deeper slope on exercise for patients indicating a loss of synchrony in diastole, too. All results are presented in Abstract 81 table 1.

\section{Abstract 81 Table 1}

\begin{tabular}{llllllr}
\hline & $\begin{array}{l}\text { Patients } \\
\text { Rest }\end{array}$ & $\begin{array}{l}\text { Controls } \\
\text { Rest }\end{array}$ & $\begin{array}{l}\text { Patients } \\
\text { p value Exercise }\end{array}$ & $\begin{array}{l}\text { Controls } \\
\text { Exercise }\end{array}$ & p value \\
\hline Apical Rotation $\left({ }^{\circ}\right)$ & $9.9 \pm 4.4$ & $13.4 \pm 4.0$ & $<0.001$ & $12.5 \pm 4.7$ & $16.6 \pm 3.9$ & $<0.001$ \\
Basal Rotation $\left({ }^{\circ}\right)$ & $-8.3 \pm 3.3$ & $-8.0 \pm 3.4$ & 0.676 & $-7.7 \pm 3.2$ & $-9.7 \pm 3.0$ & 0.011 \\
Twist $\left({ }^{\circ}\right.$ ) & $18.0 \pm 5.7$ & $21.0 \pm 4.9$ & 0.01 & $19.5 \pm 5.9$ & $25.9 \pm 6.0$ & $<0.001$ \\
SD Systolic Motions (ms) & $48.6 \pm 32.9$ & $43.1 \pm 25.3$ & 0.38 & $40.1 \pm 27.1$ & $25.9 \pm 15.5$ & 0.01 \\
Ratio Untwist/Extension & $25.3 \pm 51.4$ & $7.1 \pm 10.7$ & 0.059 & $9.6 \pm 14.7$ & $3.3 \pm 3.8$ & 0.034 \\
in IVRT $(\% / m m)$ & & & & & & \\
\end{tabular}

Conclusion Patients with HFNEF show a deterioration of basal rotation and a systolic and diastolic three plane dyssynchrony particularly on exercise. This might further contribute to the deterioration of early diastolic suction and therefore decrease stroke volume on exercise. This might be a major contribution to their symptoms.

\section{MANAGEMENT OF ADVANCED HEART FAILURE IN THE UK: TRENDS IN HEART TRANSPLANTATION AND MECHANICAL CIRCULATORY SUPPORT}

doi:10.1136/heartjnl-2011-300198.82

${ }^{1} \mathrm{~A}$ Emin, ${ }^{2} \mathrm{C}$ A Rogers, ${ }^{3} \mathrm{H} \mathrm{L}$ Thomas, ${ }^{4} \mathrm{~S}$ Tsui, ${ }^{5} \mathrm{~S}$ Schueler, ${ }^{5} \mathrm{G}$ MacGowan, ${ }^{6} \mathrm{~A}$ Simon, ${ }^{7} \mathrm{R}$ S Bonser, ${ }^{4} \mathrm{~J}$ Parameshwar, ${ }^{8} \mathrm{~N}$ R Banner. ${ }^{1}$ Clinical Effectiveness Unit, The Royal College of Surgeons of England, London, UK; ${ }^{2}$ Clinical Trials and Evaluation Unit, University of Bristol, Bristol, UK; ${ }^{3}$ NHS Blood and Transplant, Bristol, UK; ${ }^{4}$ Cardiopulmonary Transplantation, Papworth Hospital NHS Foundation Trust, Cambridge, UK; ${ }^{5}$ Cardiopulmonary Transplantation, Freeman Hospital, Newcastle, UK; ${ }^{6}$ Heart and Lung Transplantation, Royal Brompton and Harefield NHS Trust, Middlesex, UK; ${ }^{7}$ Cardiopulmonary Transplantation, Queen Elizabeth Hospital, University of Birmingham, Birmingham, UK; ${ }^{8}$ Royal Brompton and Harefield NHS Trust - on behalf of the UK VAD Forum and UKCTA Steering Group, Middlesex, UK

Introduction Patients with advanced heart failure due to systolic ventricular dysfunction require "pump replacement" therapy. Previously, heart transplantation (HTx) met this need but waiting times have increased due to shortage of donor hearts. Consequently, more patients require a ventricular assist device (VAD) as a bridge to transplant (BTT). We report UK activity, trends and outcome for HTx and BTT VAD.

Methods Data were acquired from a comprehensive national database using 3 eras for analysis: E1: 5/2002-12/2004, E2: 1/2005-12/ 2007 \& E3: 1/2008-6/2010. Paediatric and multi-organ transplants were excluded from the transplant cohort. Patients who received prior short-term support (bridge to bridge) were excluded from the VAD group.

Results 1278 patients were listed for HTx over the 3 eras: E1 155 per year, E2 165 per year, E3 148 per year. The number of adult HTx fell from 132 per year in E1 to 94 per year in E3. The median waiting time for non-urgent HTx increased from 87 days in E1 (95\%CI 55 to 119) to 321 days in E3 (95\%CI 203 to 439$)$ ( $p<0.001)$. 239 patients needed left VAD support as BTT; 75 (31\%) also received a right VAD. Activity rose from 26 per year in E1 to 41 per year in E3. Device 
choice has changed in favour of rotary pumps; 19\%, 69\% and $96 \%$ for E1, E2 and E3 respectively. Median duration of VAD support increased from 84 days (IOR 20-209) in E1 to 280 days (IOR $86-661)$ in E3 $(\mathrm{p}<0.01)$. Overall survival to 1 year after $\mathrm{VAD}$ implant rose from $52.9 \%$ (95\%CI 40 to 64$)$ in E1 to $65.6 \%(95 \%$ CI 54 to 75$)$ in $\mathrm{E} 3(\mathrm{p}=0.10)$. Of the 239 patients implanted, $83(35 \%)$ have undergone HTx, 52 (22\%) are alive on VAD support \& 84 (35\%) died on support. Twenty were explanted following myocardial recovery; 18 of these remain alive \& 2 died. Survival after HTx for patients with or without a pre-HTx VAD was $81.4 \%(95 \%$ CI 71 to 88$) \&$ $90.3 \%(95 \%$ CI 88 to 92$)$ respectively at 30 -days $(\mathrm{p}<0.01)$ and $80.0 \%$ (95\%CI 63 to 82$) \& 84.3 \%$ (95\%CI 82 to 87 ) respectively at 1 -year $(\mathrm{p}<0.01)$. 1-year survival conditional on 30-day survival was similar with \& without a pre-HTx VAD (93\% vs $91 \%$, p=0.48).

Conclusion Heart transplant activity has declined and waiting times have become prolonged leading to an increased need for bridging to transplantation. There has been a shift from volume displacement VADs to rotary blood pumps and the duration of support has increased. Post VAD survival has improved. While bridging appears to increase mortality early after HTx, longer term survival is unaffected.

\section{CLINICAL AND HAEMODYNAMIC STATUS BEYOND 3 MONTHS OF MECHANICAL SUPPORT WITH THE HEARTWARE VENTRICULAR ASSIST DEVICE}

doi:10.1136/heartjnl-2011-300198.83

B Gordon, A McDiarmid, N Robinson, N Wrightson, G Parry, S Schueler, G MacGowan. Freeman hospital, Newcastle upon Tyne, UK

Introduction Limited data exist on the longer term clinical and haemodynamic impact of the HeartWare left ventricular assist device (HVAD $\left.{ }^{\circledR}\right)$ when used as a bridge to heart transplantation. Patients who had a device longer than 3 months were reviewed.

Methods 26 patients had a HVAD implanted from 07/2009 to 07/ 2010 (mean age 46.8 years, 18 male, 5174 total days of support). Baseline and follow-up NYHA functional class, peak VO2 (bicycle exercise), right heart haemodynamics, biochemistry and mortality outcome were compared using paired t test. Results: 22/26 (85\%) patients survived beyond 3 months. 4 patients died before (mean survival 40 days, 2 stroke and 2 multi-organ failure) and 2 died after (mean survival 173 days, 1 stroke, 1 right heart failure) discharge from hospital. 2 patients were transplanted (at 3 and 241 days after implant) and 1 had recovery of LV function. Follow-up data is available for 14/20 survivors (mean 197 days from implant). Significant results are shown in the Abstract 83 table 1 . There was no significant change in peak $\mathrm{VO}_{2}(9.9 \pm 1.8$ to $12.9 \pm 3.8, \mathrm{p}=0.08)$, haemoglobin $(12.7 \pm 1.7$ to $12.1 \pm 1.2, \mathrm{p}=0.3)$ or creatinine $(122 \pm 41$ to $105 \pm 38, \mathrm{p}=0.19)$.

\section{Abstract 83 Table 1}

\begin{tabular}{lccc}
\hline Parameter & Baseline & Follow-up & p Value \\
\hline NYHA functional class & $3.6 \pm 0.4$ & $2.1 \pm 0.6$ & $<0.001$ \\
Mean PA pressure (mm Hg) & $38 \pm 9$ & $21 \pm 8$ & $<0.001$ \\
Mean PW pressure (mm Hg) & $25 \pm 5$ & $10 \pm 5$ & $<0.001$ \\
Transpulmonary gradient (mm Hg) & $12 \pm 5$ & $9 \pm 3$ & 0.02 \\
Right atrial pressure (mm Hg) & $11 \pm 6$ & $5 \pm 4$ & 0.006 \\
PA oxygen saturation (\%) & $51 \pm 8$ & $66 \pm 7$ & 0.003 \\
Cardiac Output (I/min) & $2.9 \pm 0.8$ & $4.3 \pm 0.9$ & $<0.001$ \\
Sodium (mmol/l) & $134 \pm 4$ & $139 \pm 3$ & 0.002 \\
\hline
\end{tabular}

Conclusions The HVAD ${ }^{\circledR}$ results in significant improvement in functional class, right heart haemodynamics, cardiac output and sodium levels beyond 3 months of therapy. Ongoing randomised clinical trials will establish the long-term outcome of this device.
84 TREATMENT OF REFRACTORY RIGHT HEART FAILURE AFTER IMPLANTATION OF A LEFT VENTRICULAR ASSIST DEVICE. IS THE LEVITRONIX CENTRIMAG RIGHT HEART SUPPORT A SOLUTION?

doi:10.1136/heartjnl-2011-300198.84

B Zych, A F Popov, A Barsan, M Hedger, R Hards, N R Banner, A R Simon. Royal Brompton\&Harefield NHS Foundation Trust, Harefield Hospital, Harefield, UK

Introduction Right heart failure after left Ventricular Assist Device (LVAD) implantation is a severe complication, in extreme cases necessitating additional mechanical assist. We present our institutional experience with the Levitronix CentriMag used for right ventricular support commencing LVAD implantation with refractory right ventricular failure.

Material and Methods Between March 2001 and November 2010109 patients underwent implantation of long term, total implantable, continuous flow LVADs: 60 HeartMate II, 25 Jarvik 2000 and 24 HeartWare. All patients requiring right ventricular support were included $(n=24)$, for which the Levitronix CentriMag continuous flow, paracorporeal device was used. The analysis included patient demographics as well as overall duration of support and outcome parameters, including survival at 30, 90 days and 1 year.

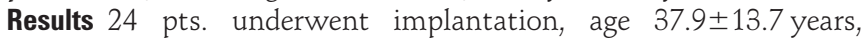
gender: M/F-15/9, underlying disease: dilated cardiomyopathy 22 (92\%), peripartum cardiomyopathy $1(4 \%)$, viral myocarditis $1(4 \%)$. Median duration of support: 28 days (5-146). 3(12.5\%) pts. underwent heart transplantation (HTx) on RV support, $14(58.5 \%)$ underwent RVAD explantation. Of these, 3 underwent successful HTx, 4 recovered LV function and underwent successful LVAD explantation, 3 remain on continuing LVAD support, 4 patients died after RVAD explantation (post explantation day 1, months 3 and 4 and at 2 years), 7(29\%) patients died during RV support. Median ITU/hospital stay: 19.5 days (6-145)/78.5 days (10-219). 30-day/ 90-day/1-year survival: 79\%/71\%/60\%. 15(62.5\%) patients were discharged from hospital after treatment. Median survival after procedure: 473.5 days (10-1917).

Conclusion Levitronix CentriMag right ventricular support is an excellent option for post LVAD implantation treatment of refractory RV failure. It allows either bridging to transplantation or RV function improvement and provides an acceptable rate of survival.

\section{PREDICTION OF RESPONSE TO BIVENTRICULAR PACING FROM DYSSYNCHRONY INDICES: THE ABSOLUTE LIMIT ON PREDICTABILITY, AND ITS CLINICAL IMPLICATIONS}

doi:10.1136/heartjnl-2011-300198.85

${ }^{1} \mathrm{~S} S$ Nijjer, ${ }^{2} \mathrm{P}$ Pabari, ${ }^{3} \mathrm{~B}$ Stegemann, ${ }^{4} \mathrm{~V}$ Palmieri, ${ }^{5} \mathrm{~N}$ Freemantle, ${ }^{2} \mathrm{~A}$ Hughes, ${ }^{2} \mathrm{D}$ P Francis. ${ }^{1}$ Imperial College Healthcare NHS Trust, London, UK; ${ }^{2}$ Imperial College London, London, UK; ${ }^{3}$ Medtronic Bakken Research Center, Maastricht, The Netherlands; ${ }^{4}$ Ospedale dei Pellegrini, Naples, Italy; ${ }^{5}$ University of Birmingham, Birmingham, UK

Background It may be incorrect to believe that, with a good echocardiographic marker of mechanical dyssynchrony, response to biventricular pacing (BVP) should be predictable with a high $\mathrm{r}^{2}$ value. Variability between repeat echocardiographic measurements, and between successive dyssynchrony measurements, may reduce $r^{2}$. Both will mandatorily limit the achievable $r^{2}$; we determine this "contraction factor".

Method and Results We compared correlation coefficients of dyssynchrony indices with response markers, in externally monitored randomised controlled trials (EMRCTs) and highly skilled single centre studies (HSSCSs). $\triangle$ LVEF in CRT recipients comprises true CRT effect plus unpredictable spontaneous variability present in control patients (Abstract 85 figure 1, upper panel). The resultant depression in $r^{2}$ is calculated. HSSCSs overstate $r^{2}$ between 